\title{
Application of Streptococcus thermophilus DPC1842 as an adjunct to counteract bacteriophage disruption in a predominantly lactococcal Cheddar cheese starter: use in bulk starter culture systems
}

\author{
Daire StOKES ${ }^{\mathrm{a}, \mathrm{b}}$, R. Paul Ross ${ }^{\mathrm{a}}$, Gerald F. FitzGerald ${ }^{\mathrm{b}}$, \\ Aidan COFFEY ${ }^{\mathrm{a} *}$ \\ a Dairy Quality Department, TEAGASC Dairy Products Research Centre, \\ Moorepark, Fermoy, Co. Cork, Ireland \\ ${ }^{\mathrm{b}}$ Department of Microbiology, University College, Cork, Ireland
}

\begin{abstract}
A significant amount of Cheddar cheese manufactured world-wide relies on bulk starter cultures instead of direct vat set (DVS) cultures. While the inclusion of $S$. thermophilus is sometimes used to counteract failure due to lactococcal phage in the latter system, it is considered difficult to implement in bulk starter systems and is normally avoided. This stems from the problem in controlling the ratio of $S$. thermophilus to lactococci during the bulk starter preparation such that suitable acidification rates can be achieved. The current study demonstrates how $S$. thermophilus numbers can be controlled during growth in the bulk starter medium prior to inoculation of a culture, based on three lactococcal strains and S. thermophilus DPC1842, into the cheese vat. The concentration of inorganic phosphate necessary to inhibit the growth of strain DPC1842 in a whey-based bulk starter medium was found to be $0.18 \mathrm{~mol} \cdot \mathrm{L}^{-1}$. Since higher levels of phosphate exist in different commercial bulk starter media used for mesophilic cultures, a number of these media can be used for propagation of this starter blend without domination of strain DPC1842 over its lactococcal counterparts. Strain DPC1842 is highly phage resistant and is particularly acid-fast in the cheese milk and reduces the $\mathrm{pH}$ efficiently at very low inocula. Cheddar cheese was manufactured in a commercial plant with this system and the resulting cheese had good flavour characteristics. This study demonstrates the effectiveness of the S. thermophilus DPC1842 component in rescuing the fermentation in the event of severe lactococcal phage attack.
\end{abstract}

Streptococcus thermophilus / adjunct / Cheddar / bacteriophage

Résumé - Ajout de Streptococcus thermophilus DPC1842 à la flore lactococcale utilisée en fabrication de Cheddar pour contrecarrer les attaques phagiques : utilisation dans des systèmes de culture de levain industriel. Une partie importante du fromage de Cheddar fabriqué dans

* Correspondence and reprints

Tel.: (353) 25 42277; fax: (353) 25 42340; e-mail: acoffey @ moorepark.teagasc.ie 
le monde repose sur l'utilisation de cultures de levains industriels au lieu de cultures d'ensemencement direct en cuve. Alors que l'ajout de $S$. thermophilus est parfois utilisé dans ce dernier système pour contrecarrer la défaillance due aux phages de lactocoques, ceci est considéré comme difficile à mettre en œuvre dans les systèmes de levains industriels et est normalement évité en raison de la difficulté à contrôler, au cours de la préparation du levain industriel, le rapport $S$. thermophilus/lactocoques et donc à obtenir un taux d'acidification convenable. La présente étude montre comment le nombre de $S$. thermophilus peut être contrôlé pendant la croissance dans le milieu de culture du levain industriel avant l'inoculation dans la cuve de fromagerie d'une culture composée de 3 souches de lactocoques et de la souche de $S$. thermophilus DPC1842. La concentration de phosphate inorganique nécessaire pour inhiber la croissance de la souche DPC1842 dans le milieu de culture du levain industriel à base de lactosérum a était de $0,18 \mathrm{~mol} \cdot \mathrm{L}^{-1}$. Étant donné que différents milieux du commerce, utilisés pour des cultures mésophiles de levains industriels, renferment des concentrations supérieures de phosphates, un certain nombre de ces milieux peut être utilisé pour cultiver ce mélange de levain sans domination de la souche DPC1842 sur les lactocoques. La souche DPC1842 est très résistante aux phages, acidifie très rapidement le lait de fromagerie, et réduit le $\mathrm{pH}$ efficacement à des taux d'inoculation très bas. Du Cheddar, fabriqué commercialement selon cette technologie, présentait d'excellentes qualités aromatiques. Cette étude démontre l'efficacité de la souche de $S$. thermophilus DPC1842 pour restaurer la fermentation en cas d'attaque sévère par les phages de lactocoques.

\section{Streptococcus thermophilus / Cheddar / bactériophage}

\section{INTRODUCTION}

Cheddar cheese starters are nowadays generally composed of 2-6 well-characterised Lactococcus lactis strains which are chosen for their fast acid-producing ability and their high phage insensitivity [11] and their ability to perform within stringent manufacturing schedules. Currently in the cheese industry, manufacturers are relying to an increasing extent on small numbers of lactococcal strains for a reliable process and a consistent high quality end product. The destructive potential of phage is exaggerated in modern processes which employ cultures on a continuous basis and where huge numbers of starter cells are required to process large volumes of milk to cheese. Despite the fact that cheese-making strains are initially chosen on the basis of phage resistance, they frequently become susceptible to phages, which emerge after extended use in the cheese plant $[1,6,8,13]$. Important sources of these phages include the external environment and evolution from pre-existing phages within the cheese plants themselves $[4,6]$. The use of $S$. thermophilus strains as phage-unrelated starter components with lactococci in direct-vat-set (DVS) cheese cultures for use in mesophilic fermentations is common [7]. The reasoning behind this is that $S$. thermophilus will continue to produce acid in the cheese vat in the event of phage associated disturbances of the lactococcal starter components. Since a significant amount of Cheddar cheese production relies on bulk starter cultures instead of DVS cultures, the inclusion of $S$. thermophilus can be difficult and is normally avoided. This stems from the problem in controlling the ratio of $S$. thermophilus to lactococci during the bulk starter preparation such that suitable acidification rates can be achieved in the cheese vat. This study demonstrates an effective control of the ratio of $S$. thermophilus to lactococci from the time of inoculation of bulk starter (with a blend of streptococci and lactococci) to cheese manufacture. It also shows the effectiveness of the $S$. thermophilus DPC1842 component in completing the fermentation in the event of severe lactococcal phage attack where in excess of $99.9 \%$ of the Lactococcus population was eliminated. 


\section{MATERIALS AND METHODS}

\subsection{Bacterial strains, bacteriophage and media used}

The bacteria and bacteriophage used in this study were obtained from the culture collection at the Dairy Products Research Centre. Strains of L. lactis were propagated in either $10 \%(\mathrm{w} / \mathrm{v})$ reconstituted skim milk (RSM), or M17 medium (Difco Laboratories, Detroit, USA) at $30{ }^{\circ} \mathrm{C}$ and supplemented with $0.5 \%(\mathrm{w} / \mathrm{v})$ lactose (LM17). Strains of $S$. thermophilus were propagated in LM17 medium or RSM at $42{ }^{\circ} \mathrm{C}$. Commercially available bulk starter medium was heated to $90{ }^{\circ} \mathrm{C}$ for $30 \mathrm{~min}$ prior to use. To aid in differentiating between lactococci and streptococci in mixed starter populations, X-Gal (5-Bromo-4-chloro-3-indolyl$\beta$-galactoside) was incorporated into LM17 at a final concentration of $0.02 \%$. L. lactis produced white colonies and S. thermophilus produced small blue colonies when grown on LM17 containing X-Gal. Non-starter lactic acid bacteria (NSLABs) from cheese were enumerated on LBS agar as described previously [16].

\subsection{Characterisation of acid- production by starter strains}

Cheddar cheese temperature profiles (CTP) were employed to assess acid producing ability of starter strains in milk as described previously [5].

\subsection{Laboratory scale cheese manufacture}

Laboratory scale cheese trials were performed using $2 \mathrm{~L}$ of pasteurised whole milk, which was heated to $32{ }^{\circ} \mathrm{C}$ prior to inoculation. A $1.5 \%$ inoculum was added and stirred for 35 min until a $\mathrm{pH}$ of 6.6 had been achieved. Chymax-Plus rennet (Chr. Hansen Laboratories, Little Island, Cork, Ireland) at a concentration of $0.18 \mathrm{ml} \cdot \mathrm{L}^{-1}$ was then added. The milk was allowed to set for approximately $40 \mathrm{~min}$ after which the curd was cut using a sharp knife. The curd was then cooked at $38{ }^{\circ} \mathrm{C}$. Whey was drained when curd reached a $\mathrm{pH}$ of 6.1. $\mathrm{pH}$ of curd was monitored periodically until it reached 5.2 when it was placed in small plastic cylindrical cheese moulds with draining pores of $3 \mathrm{~mm}$ in diameter (Cat. No. $3404 \mathrm{~m}$, Smallholding supplies, Pikes farmhouse, Somerset, UK). Curd was pressed overnight at $4{ }^{\circ} \mathrm{C}$ and ripened as required.

\subsection{Measurement of intracellular enzyme release in cheese curd}

Following cheese manufacture including overnight pressing, triplicate samples of cheese curd were placed in $10 \mathrm{~mL}$ tubes and centrifuged at $50000 \mathrm{rpm}$ for $30 \mathrm{~min}$ at $4{ }^{\circ} \mathrm{C}$ in a Sorvall ${ }^{\circledR}$ OTD65B ultracentrifuge. Curd juice was removed from the tube and assayed for lactate dehydrogenase (LDH), an intracellular marker enzyme indicating cell lysis. This was performed using the method of Wittenberger and Angelo [18], which measures the decrease in absorbance at $340 \mathrm{~nm}$ resulting from the pyruvate dependant oxidation of NADH. LDH activity was expressed as activity units (AU) per $\mathrm{mL}$ of juice, where 1 unit is the amount of enzyme that catalyses the oxidation of $1 \mu$ mole of NADH per min per mL. The LDH levels presented are the averages of those obtained from triplicate analyses of cheese curds.

\subsection{Pilot-scale Cheddar cheese manufacture}

Pilot-scale cheese making trials and cheese analyses were performed as described previously [16].

\subsection{Industrial-scale Cheddar cheese manufacture}

Industrial-scale Cheddar cheese making trials and analyses were performed as 
described previously [10]. The mesophilic bulk starter medium employed by the cheese plant was PIM100 (Nutrition Supplies and Services Ltd., Inishannon, Co. Cork, Ireland).

\section{RESULTS AND DISCUSSION}

\subsection{Starter culture design}

A typical starter system for Cheddar manufacture is based on 1 or 2 acid-fast phage resistant lactococcal strains and 1 or 2 autolytic lactococcal strains which enhance starter enzyme release into the cheese. The system used in this study included 2 acidfast phage resistant lactococci, 1 autolytic Lactococcus strain with the additional component, $S$. thermophilus to ensure good acid production in the event of severe lactococcal starter inhibition due to phage. The $S$. thermophilus strains selected were not affected by bacteriophage cocktails which were inhibitory to lactococcal starters nor were they affected by existing cocktails of thermophilic phage from 2 Irish Mozzarella cheese plants.

\subsection{Performance of $S$. thermophilus during Cheddar CTP}

A number of strains of $S$. thermophilus were used as adjuncts with commercial Cheddar cheese starters in pilot scale cheese manufacture. Three strains were identified which demonstrated resistance to phages from Mozzarella plants and appeared to have no influence on Cheddar cheese flavour (data not shown). These 3 strains of $S$. thermophilus were compared for their acid producing ability in milk over the CTP. Of these, strain DPC1842 was particularly acid-fast (Fig. 1). Over the Cheddar CTP, an inoculum level of $0.025 \%$ of this strain was sufficient to reduce the $\mathrm{pH}$ of $10 \% \mathrm{RSM}$ to 5.2 within $6 \mathrm{~h}$. The ability to acidify milk efficiently at such a low inoculum has obvious advantages in situations where lactococcal components

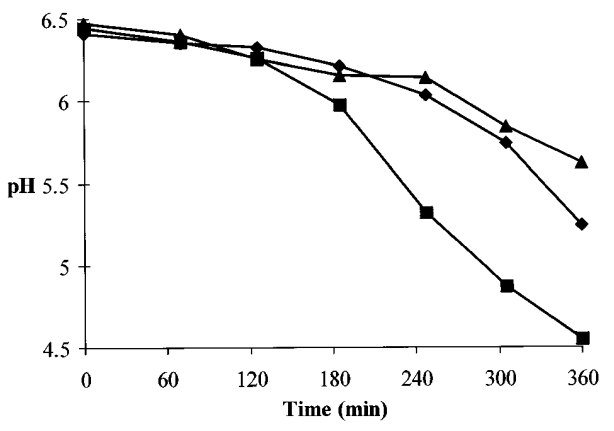

Figure 1. $\mathrm{pH}$ development in $10 \% \mathrm{RSM}$ incubated over the Cheddar cheese temperature profile with a $1.5 \%$ inoculum of $S$. thermophilus DPC1854 ( ); S. thermophilus DPC1150 (A); and $S$. thermophilus DPC1842 (

of a starter are inhibited by phage as discussed later in this communication. Importantly, this ability would suggest that the strain might have a high probability of dominating the starter population when combined and grown with lactococci in the bulk starter tank and cheese vat.

\subsection{Formulation of different starter blends}

Seven different four-strain blends were assembled. These were formulated as S. thermophilus DPC1842 with two acid-fast phage resistant lactococci and one autolytic lactococcal strain at a ratio of $1: 1: 1: 2$, respectively. Rates of acid production of all blends in milk incubated over the Cheddar cheese temperature profile were monitored. Two blends were chosen for pilotscale Cheddar manufacture due to their superior acid-producing capabilities. These were blend 1: S. thermophilus DPC1842/L. lactis DPC4830/L. lactis DPC4987/ L. lactis DPC4991 (autolytic) and blend 2: S. thermophilus DPC1842/L. lactis DPC5020/L. lactis DPC4988/L. lactis DPC4990 (autolytic) which could reduce the $\mathrm{pH}$ of milk to 4.96 and 4.75 , 
respectively. Following pilot-scale cheese manufacture, cheeses were assessed for composition, body and flavour. Both cheeses graded well and compared favourably with control cheese manufactured with a commercial Cheddar cheese starter, namely 303/227 (Chr. Hansen Laboratories, Little Island, Cork, Ireland). However, the cheese made from blend 1 was considered superior to that of blend 2 on the basis of assessment by commercial cheese graders and thus blend 1 was used for the remainder of the study.

\subsection{Population dynamics of streptococci and lactococci in bulk starter media}

Commercial Cheddar cheese manufacture with bulk starter in Ireland is generally based on propagation of the starter culture in whey-based medium overnight followed by activity tests on the fully-grown bulk starter culture the following day. Typically in the Irish industry, the culture is grown in the bulk starter medium for $18 \mathrm{~h}$ at 25 to $27^{\circ} \mathrm{C}$ prior to inoculation into cheese vats. For this reason, it was important to study the population dynamics of $L$. lactis and $S$. thermophilus from the time of inoculation in the bulk starter medium through propagation and inoculation into the cheese vat and throughout cheese manufacture.

The behaviour of $S$. thermophilus in relation to lactococci was first determined in bulk starter medium (PIM100) by performing differential plate counts after inoculation $(\mathrm{T}=0)$ and after incubation at $27{ }^{\circ} \mathrm{C}$ for $18 \mathrm{~h}(\mathrm{~T}=18)$. For comparison sake, the strain L. lactis DPC4268 alone was used as the lactococcal component. The ratios tested included Lactococcus: Streptococcus at 1:0, $0: 1,1: 1$, and $3: 1$. In all cases where lactococci were present, they grew very well reaching approximately $10^{10} \mathrm{cfu} \cdot \mathrm{mL}^{-1}$ of bulk starter medium at $\mathrm{T}=18$. In contrast, with S. thermophilus, the counts at $\mathrm{T}=18$ were never greater than the count at $\mathrm{T}=0$ indicating that $S$. thermophilus DPC1842 did not grow in the bulk starter medium under these conditions even when no lactococci were present. The same result was observed in another commonly used mesophilic bulk starter medium namely Economie 6 (Rhodia Texel, Ltd., UK).

\subsection{Inorganic phosphate in bulk starter medium inhibits growth of $S$. thermophilus DPC1842}

Commercial bulk starter media are generally prepared from deionised whey supplemented with protein hydrolysates, ammonium and sodium phosphate salts [2, 17]. Mesophilic bulk starter media also contain high levels of inorganic phosphates [3, 9 , $15]$, which have been found to inhibit the activity of $\beta$-galactosidase in $S$. thermophilus [14]. The growth of strain DPC1842 was analysed in a model starter medium based on demineralised whey $(10 \%)$, yeast extract $(0.5 \%)$ and ascorbic acid $(0.05 \%)$ [15]. This was supplemented with $\mathrm{Na}_{2} \mathrm{HPO}_{4}$ at a variety of concentrations ranging from $0.01 \mathrm{~mol} \cdot \mathrm{L}^{-1}$ to $0.25 \mathrm{~mol} \cdot \mathrm{L}^{-1}$. It was observed, after incubation at $27^{\circ} \mathrm{C}$ for $18 \mathrm{~h}$, that $0.18 \mathrm{~mol} \cdot \mathrm{L}^{-1} \mathrm{Na}_{2} \mathrm{HPO}_{4}$ was the threshold level at which the number of $S$. thermophilus DPC1842 at $\mathrm{T}=18$ did not exceed the number at $\mathrm{T}=0\left(8.5 \times 10^{6} \mathrm{cfu} \cdot \mathrm{mL}^{-1}\right)$ (Fig. 2a). In the absence of $\mathrm{Na}_{2} \mathrm{HPO}_{4}$, DPC1842 reached $1.1 \times 10^{9} \mathrm{cfu} \cdot \mathrm{mL}^{-1}$. Lactococcal growth, on the other hand, generated a final count of $7.9 \times 10^{9} \mathrm{cfu} \cdot \mathrm{mL}^{-1}$ in the presence of $0.18 \mathrm{~mol} \cdot \mathrm{L}^{-1} \mathrm{Na}_{2} \mathrm{HPO}_{4}$ (Fig. 2b). These trends were also evident in both of the commercial mesophilic bulk starter media examined. From these observations, we conclude that $S$. thermophilus DPC1842 can be present at a similar level to any of the L. lactis components at the time of inoculation into the bulk starter medium without any risk of out-competing the lactococci. 

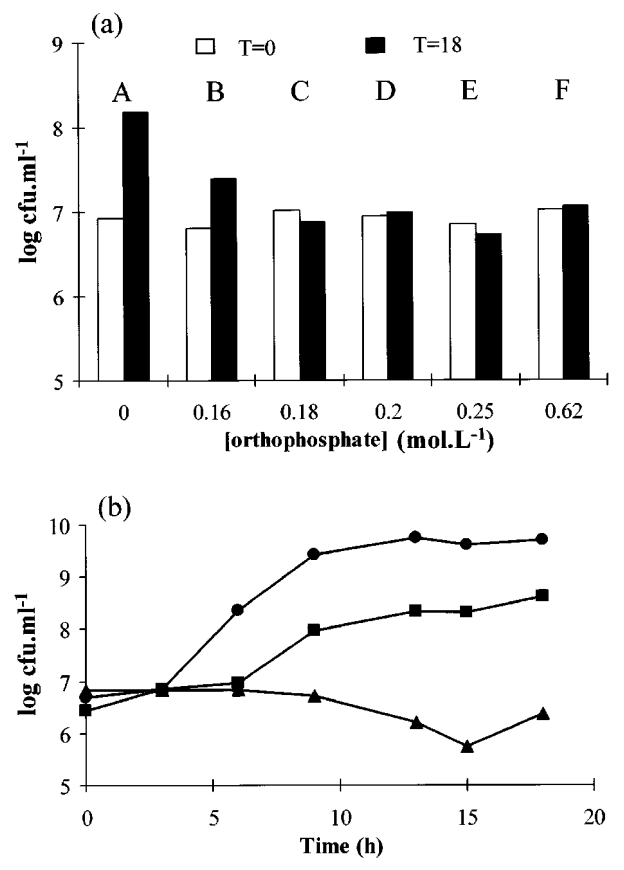

Figure 2. (a) Inhibitory effect of increasing orthophosphate concentration on the growth of $S$. thermophilus DPC1842 in a whey-based medium supplemented with (A) no phosphate; (B) $0.16 \mathrm{~mol} \cdot \mathrm{L}^{-1}$ orthophosphate; (C) $0.18 \mathrm{~mol} \cdot \mathrm{L}^{-1}$ orthophosphate; (D) $0.2 \mathrm{~mol} \cdot \mathrm{L}^{-1}$ orthophosphate; (E) $0.25 \mathrm{~mol} \cdot \mathrm{L}^{-1}$ orthophosphate compared with (F) Commercial bulk starter medium. Bacterial counts were taken at time zero (white) and after $18 \mathrm{~h}$ (black). (b) Growth characteristics of $S$. thermophilus DPC1842 in medium A above (no $\mathrm{Na}_{2} \mathrm{HPO}_{4}$ ) and $\mathrm{C}$ above $(\boldsymbol{\Delta})\left(0.18 \mathrm{~mol} \cdot \mathrm{L}^{-1}\right.$ $\mathrm{Na}_{2} \mathrm{HPO}_{4}$ ) and L. lactis DPC4932 in medium C $(\bullet)^{2}$.

\subsection{Challenge of a typical lactococcal component of the starter with lytic phage during growth in cheese milk}

A laboratory-scale model of the starter blend was made combining $S$. thermophilus DPC1842 with a commonly used lactococcal starter for which a highly virulent prolate-headed phage was available (namely phage 4932). L. lactis DPC4932 and S. thermophilus DPC1842 were grown (1:1) in commercial bulk starter medium for $18 \mathrm{~h}$ at $27{ }^{\circ} \mathrm{C}$. This culture was used to inoculate pasteurised milk which was subsequently shown to contain $9 \times 10^{7} \mathrm{cfu}$ L. lactis per $\mathrm{mL}$ of milk at time zero (Fig. 3). The sample was incubated over the CTP. Acid development and lactococcal versus streptococcal counts were monitored. In samples where $\phi 4932$ (approximately $10^{5}$ plaque forming units. $\mathrm{mL}^{-1}$ cheese milk at time zero) was included, the $\mathrm{pH}$ still reached 5.2 when DPC1842 was present, even though counts of lactococci went as low as $2.4 \times 10^{5} \mathrm{cfu} \cdot \mathrm{mL}^{-1}$ in the cheese milk due to the presence of disturbing phage. In this case, the time required to reach $\mathrm{pH} 5.2$ was on average 60 min longer than when phage were excluded. It is, however, noteworthy that this is an extreme case in which more than 99.9\% of the lactococci had been eliminated by phage. Even in this instance, which could be viewed as the worst possible case scenario, $S$. thermophilus DPC1842 did reduce the $\mathrm{pH}$ sufficiently in the cheese milk.

\subsection{Commercial cheese manufacture}

Two commercial trials were performed at an industrial cheese plant with the Lactococcus/Streptococcus blend 1. Cheeses were assessed on the basis of composition and flavour at 6 months. Cheese compositional analysis after 6 months ripening indicated that the test cheese had a $\mathrm{pH}$ of 5.17, a salt-in-moisture $(\mathrm{S} / \mathrm{M})$ of 5.50 , a protein content of $25.72 \%$ and moisture in non-fat substance (MNFS) was $55.50 \%$. These values were within parameters expected for Cheddar cheese [12]. Commercial cheese graders assessed cheese flavour, body and texture and the test compared well with premium Cheddar manufactured with commercial starter cultures on the same day. Changes in populations of the L. lactis and $S$. thermophilus components and NSLABs during ripening of the Cheddar made with 


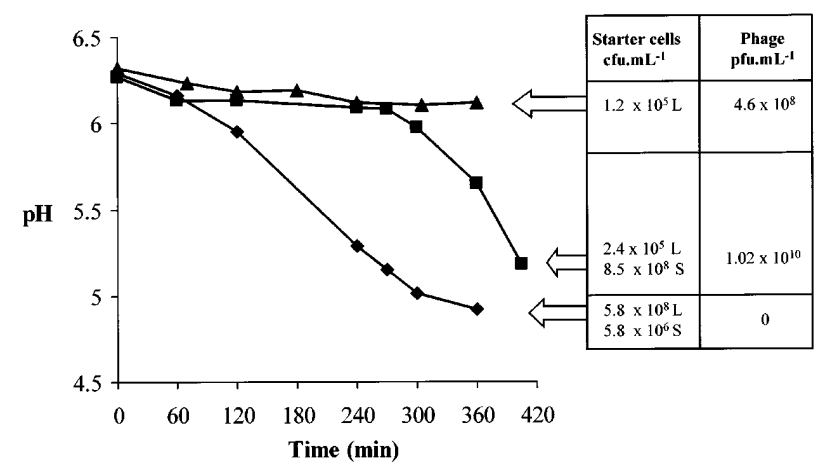

Figure 3. $\mathrm{pH}$ development over the CTP in 10\% RSM containing S. thermophilus DPC1842 and L. lactis DPC4932 ( ); S. thermophilus DPC1842, L. lactis DPC4932 and lytic phage 4932 (ם); L. lactis DPC4932 and phage $4932(\boldsymbol{\Delta})$. Cell numbers at the end of the CTP are shown to the right $(\mathrm{L}=$ L. lactis and $\mathrm{S}=\mathrm{S}$. thermophilus $)$. Phage titres at the end of the CTP are shown on the far right.

blend 1 are shown in Figure 4. Numbers of $S$. thermophilus gradually reduced in parallel with the reduction in numbers of L. lactis over the six-month ripening period. While numbers of $S$. thermophilus were at all times lower than those of $L$. lactis, the population dynamics of L. lactis and NSLAB behaved as expected [16].

\subsection{Starter autolysis in cheese curd}

The effect of including the autolytic strain DPC4991 in the starter blend on intracellular enzyme release was demonstrated by analysing one-day-old cheese curds which had been manufactured with blend 1 and a variation of this blend which was lacking strain DPC4991. There was a significant difference in LDH release between the two curds. When DPC4991 was present an LDH level of $0.12 \mathrm{AU} \cdot \mathrm{mL}^{-1}$ was obtained from cheese juice which was significantly higher than when DPC4991 was absent $\left(0.07 \mathrm{AU} \cdot \mathrm{mL}^{-1}\right)$. This would indicate the role of DPC4991 in enhanced starter cell lysis and concomitant release of intracellular lactococcal enzymes, which are considered to have a positive impact on Cheddar cheese ripening and flavour.

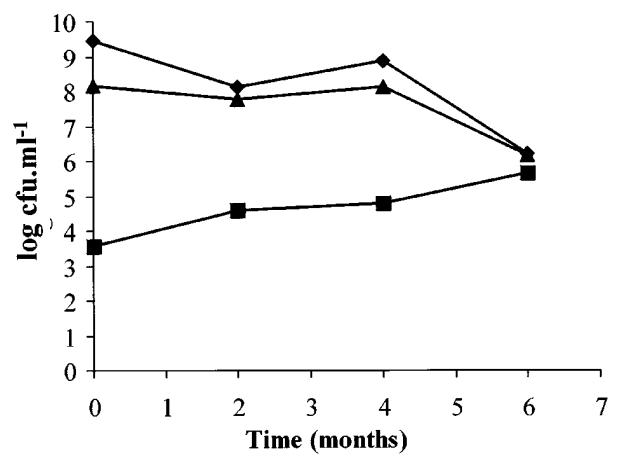

Figure 4. Survival of starter (S. thermophilus $(\boldsymbol{\Delta}) ;$ L. lactis $(\bullet))$ and NSLABs $(\boldsymbol{\square})$ in ripening Cheddar from commercial trial, made with S. thermophilus DPC1842; L. lactis DPC4830; L. lactis DPC4987; L. lactis DPC4991.

\section{CONCLUSION}

A number of approaches have been employed to combat the ever-present phage threat in the cheese industry $[1,6,8,13]$. The strategy used in this study will result in sufficient acid development in cheese milk in the event of severe phage inhibition of $L$. lactis strains. The starter blend described is adapted for propagation as a bulk starter 
culture. Under the conditions encountered during bulk culture preparation and Cheddar cheese manufacture, it was shown that the phosphate levels present in mesophilic bulk starter media prevented $S$. thermophilus from overtaking the lactococci unless phage inhibition occurred. Thus $S$. thermophilus DPC1842 demonstrated the capacity to rescue the Cheddar fermentation during severe phage attack. These observations may be important for both the design of bulk starter media for culture propagation and for the application of $S$. thermophilus strains as adjuncts in bulk starter cultures.

\section{ACKNOWLEDGMENTS}

This research has been part-funded by grant aid under the Food Sub-Programme of the Operational Programme for Industrial Development which is administered by the Irish Department of Agriculture, Food and Forestry and supported by national and European Union funds. D. Stokes was supported by a Teagasc Walsh fellowship.

\section{REFERENCES}

[1] Allison G.E., Klaenhammer T.R., Phage resistance mechanisms in lactic acid bacteria, Int Dairy J. 8 (1998) 207-226.

[2] Andersen D.L., Boston L.R., Seleen W.A., Culture media containing whey, US Pat. No. 4020 185 (1977).

[3] Ausovanodom N., White R.S., Richardson G.H., Reduced phosphate requirements in a wheybased bacteriophage medium under $\mathrm{pH}$ control, A.D.S.A. Abstract M69, J. Dairy Sci. 56 (1973) 637.

[4] Brussow H., Bruttin A., Desiere F., Lucchini S Foley S., Molecular ecology and evolution of Streptococcus thermophilus bacteriophages a review, Virus Genes 16 (1998) 95-109.

[5] Coffey A., Coakley M., McGarry A., Fitzgerald G.F., Ross R.P., Increasing phage resistance of cheese starters: a case study using Lactococcus lactis DPC4268, Lett. Appl. Microbiol. 26 (1998) 51-55

[6] Daly C., Fitzgerald G.F., Davis R., Biotechnology of lactic acid bacteria with special reference to bacteriophage resistance, Antonie van Leeuwenhoek 70 (1996) 99-110.

[7] Elsborg K., Cheese cultures adapted to specific technologies, Eur. Dairy Mag. 4 (1997) 44-45.

[8] Forde A., Fitzgerald G.F., Bacteriophage defence systems in lactic acid bacteria, Antonie van Leeuwenhoek 76 (1999) 89-113.

[9] Hargrove R.E., McDonough F.E., Tittsler R.P. Phosphate heat treatment of milk to prevent bacteriophage proliferation in lactic cultures, J. Dairy Sci. 44 (1961) 1799-1810.

[10] Kiernan R.C., Beresford T.P., Ó Cuinn G. Jordan K.N. Autolysis of lactobacilli during Cheddar cheese ripening, Irish J. Agric. Food Res. 39 (2000) 95-106.

[11] Lawrence R.C., Heap H.A. The New Zealand starter system, Bull. Int. Dairy Fed. 199 (1986) 14-20.

[12] Lawrence R.C., Gilles J., Creamer L.K., Cheddar cheese and related dry-salted cheese varieties, in: Fox P.F. (Ed), Cheese: Chemistry, Physics and Microbiology, Vol. 2, Chapman \& Hall, Londres, 1993, pp. 1-38.

[13] Moineau S., Applications of phage resistance in lactic acid bacteria, Antonie van Leeuwenhoek 76 (1999) 377-382.

[14] Ramana-Rao M.V., Dutta S.M., Production of $\beta$-galactosidase from Streptococcus thermophilus grown in whey, Appl. Environ. Microbiol. 34 (1977) 185-188.

[15] Richardson G.H., Cheng C.T., Young R., Lactic bulk culture system utilising a whey-based bacteriophage inhibitory medium and $\mathrm{pH}$ control, J. Dairy Sci. 60 (1977) 378-386.

[16] Ryan M.P., Rea M.C., Hill C., Ross R.P., An application in cheddar cheese manufacture for strain of Lactococcus lactis producing a nove broad-spectrum bacteriocin, Lacticin 3147, Appl. Environ. Microbiol. 62 (1996) 612-619.

[17] Whitehead W.E, Ayres J.W, Sandine W.E., A review of starter media for cheese making, J. Dairy Sci. 76 (1993) 2344-2353.

[18] Wittenberger C.L, Angelo L., Purification and properties of a fructose-1, 6-diphosphate-activated lactate dehydrogenase from Streptococcus faecalis, J. Bacteriol. 101 (1970) 717-724. 